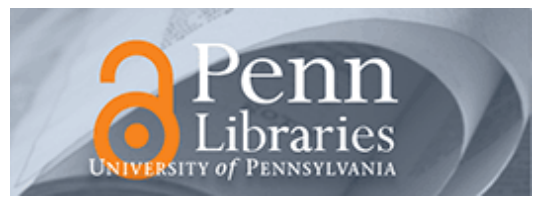

University of Pennsylvania ScholarlyCommons

Marketing Papers

Wharton Faculty Research

$1-2007$

\title{
Putting the Organization on Wheels: Workplace Design at SEI
}

Alfred P. West

Jerry Yoram Wind

University of Pennsylvania

Follow this and additional works at: https://repository.upenn.edu/marketing_papers

Part of the Business Administration, Management, and Operations Commons, Business Intelligence Commons, Human Resources Management Commons, Labor Relations Commons, Management Information Systems Commons, Marketing Commons, and the Organizational Behavior and Theory Commons

\section{Recommended Citation}

West, A. P., \& Wind, J. (2007). Putting the Organization on Wheels: Workplace Design at SEl. California Management Review, 49 (2), 138-153. http://dx.doi.org/10.2307/41166387

This paper is posted at ScholarlyCommons. https://repository.upenn.edu/marketing_papers/290

For more information, please contact repository@pobox.upenn.edu. 


\title{
Putting the Organization on Wheels: Workplace Design at SEI
}

\author{
Abstract \\ When a new employee joins SEl, it is an unusual experience. The new hire is given a map and sent down \\ to a storeroom on the lower floor of the main building. There, the employee is issued a chair and desk, \\ both on wheels, with a computer and phone on the desktop. The map shows where in the complex of nine \\ barn-like buildings on the corporate campus in Oaks, Pennsylvania, the new hire will initially be located. \\ The employee then rolls the desk through the buildings, into the oversized elevators designed for this \\ purpose, past hallways filled with a provocative (and sometimes shocking) collection of emerging \\ contemporary art.

\section{Disciplines} \\ Business | Business Administration, Management, and Operations | Business Intelligence | Human \\ Resources Management | Labor Relations | Management Information Systems | Marketing | \\ Organizational Behavior and Theory
}


California Management Review Special Issue on Workplace Design

Putting the Organization on Wheels: How SEI Uses Workplace Design and Art To Create a Corporate Culture That Drives Innovation and Growth

\author{
Alfred P. West, Jr. \\ Chairman and CEO \\ SEI \\ Yoram (Jerry) Wind \\ The Lauder Professor and Professor of Marketing \\ Director, SEI Center for Advanced Studies in Management \\ The Wharton School, University of Pennsylvania
}

Draft: June 8, 2006 


\section{California Management Review Special Issue on Workplace Design \\ Draft: June 8, 2006 \\ Putting the Organization on Wheels: How SEI Uses Workplace Design and Art To Create a Corporate Culture That Drives Innovation and Growth}

When a new employee joins SEI, it is an unusual experience. The new hire is given a map and sent down to a storeroom on the lower floor of the main building. There, the employee is issued a chair and desk, both on wheels, with a computer and phone on the desktop. The map shows where in the complex of nine barn-like buildings on the corporate campus in Oaks, Pennsylvania, the new hire will initially be located. The employee then rolls the desk through the buildings, into the oversized elevators designed for this purpose, past hallways filled with a provocative (and sometimes shocking) collection of emerging contemporary art.

In a large, open room, filled with similar desks on wheels, the employee finds the spot on the map, nudges neighboring desks aside and pulls down a thick, red wire that snakes down from the ceiling, containing computer, phone and electrical connections. Once this “python” is plugged in, the company computer recognizes the new employee and routes calls or visitors to the location. Welcome to work.

The message from Day One is clear. This is an organization that is flexible, creative and ready for constant transformation. The company is open and not hierarchical. The atmosphere and dress code is business casual. There are no corner offices - or offices at all. There is no need for an open-door policy because there are no doors. Employees are empowered. They can pick up their entire "office” and move to another location to join another team. On average, with the exception of a few anchored departments, they will relocate about twice a year. This may sound 
unsettling - but that is the point. In a world in which the business environment can change overnight, particularly in financial services, this design gives SEI the flexibility and the mindset to transform itself just as quickly.

While this might not work for every organization, the buildings and artwork at SEI are designed to reflect the culture of the organization. This environment has helped to make SEI a perennial member of Fortune's list of "Best Companies To Work for in America." This culture and approach, even before its more complete realization in the Oaks offices, has given the organization the creativity and flexibility to undergo many transformations as it has grown from a small startup in 1968 to a firm that is a leading provider of investment accounting and administrative services, processing over $\$ 50$ trillion of investment transactions annually, administering \$320 billion in mutual fund and pooled assets, and managing more than \$135 billion in investments. SEI operates 22 offices in 12 countries. This article examines the unique design of SEI's environment, the impact of the environment on the organization, and lessons learned from this ongoing and self-organizing experiment.

\section{CHALLENGES OF INFUSING CULTURE}

Corporate cultures are the glue that hold organizations together, aligning individual action and motivating collective strategy. They are norms and values that define how people work and think about work. Many mergers and acquisitions are undermined by mismatches between cultures. Organizational change initiatives are derailed by a culture that is at odds with the new strategic direction. On the other hand, when culture is aligned with strategy, it can be a powerful force for creativity and innovation. In particular, creating a culture of fun, humor and play is associated 
with increased flexibility, competitive advantage, motivation, customer service, innovation, empowerment and creativity. ${ }^{1}$ The benefits of culture may be hard to quantify, but its absence is sorely missed.

While the importance of culture is acknowledged by researchers and practitioners alike, they also agree that it is among the fuzziest and ephemeral aspects of organizations. It is intangible, soft, holistic, and difficult to change. ${ }^{2}$ Organizations relentlessly attempt to encapsulate their cultures in vision and value statements - and this work is important - but cultures are inherently difficult to codify and transmit. Values on paper are sometimes at odds with practice, as dramatically illustrated by the collapse of Enron and other organizations due to ethical lapses, despite sterling statements of ethics and values.

Company visions and values suffer from vagueness and generalities, despite the best efforts of leaders and organizational consultants. For example, a 2005 survey by Spherion Corporation of more than 1,000 US workers in different organizations found that only 44 percent believed that their organizations had a widely embraced and understood corporate culture. ${ }^{3}$ More than half of these employees had no clear understanding of what their organizations stood for.

What SEI discovered is that culture could be embodied in the workplace itself. Everywhere a member of the organization turns, the culture is clearly evident, inescapable. While it may take new employees in some organizations months or years to really know what the company is about, a person who walks into the offices of SEI knows instantly. Prospective employees know immediately if this is a place where they want to work. They love it or hate it, but there are few 
lukewarm reactions. Values encapsulated in words are just not as clear and concrete as those embodied in the office itself.

\section{The Need for Flexibility}

The challenge in giving a physical presence to values, however, is that organizations need to change. While their core values may be unchanging, everything else about them may change, as Collins and Poras point out in their examples of enduring companies in Built To Last. A set of values that is baked into the fabric of the work environment is hard to change. The dilemma, therefore, is to create a work environment that clearly communicates a core set of values but also has the flexibility to be changed over time.

For SEI, since a core part of our culture is innovation and creativity, the creation of a flexible work environment supported this culture while allowing the organization to quickly change strategic direction to seize new opportunities or respond to new threats. Since many modern organizations share this need for flexibility, a flexible office space of some kind may be perfectly in line with their core values.

\section{THE SEI ENVIRONMENT}

How and why did SEI create this office space? In this instance, necessity truly was the mother of invention. Just before its move to its Oaks headquarters, SEI had undergone a significant reinvention of the organization. Such periodic reinventions are necessary for success and survival. As companies grow, a certain hardening of the arteries sets in. Mental models create blinders that make it hard to see emerging opportunities and threats. ${ }^{4}$ People become fixed in 
their ways, ignoring the changes in the business environment. Silos develop. Costs tend to escalate. Companies become arrogant and markets become mature. There is a need to reinvent the organization.

\section{Transformation}

One of the major shifts in the organization was the emphasis on teams. Teams were a way to break the traditional silos and bring together the diverse players needed to spark creativity and execute innovations. But while teamwork increased, the reality was that to move a worker from one team to another meant about $\$ 1,400$ in reconstruction costs and days of lost productivity. Walls literally had to be torn down. Workmen needed to pack up desks and furniture. The culture was flexible, open, empowered and non-hierarchical, but the buildings were not designed for this. Real estate almost always gets in the way.

Another dramatic change that preceded the move to the new headquarters was the elimination of all secretaries. Technology was developing in such a way that it was possible to design an organization without secretaries. It was one of the most awkward things the company had ever done. Some senior managers who saw a secretary as one of the perks of the job, were shocked by the move. But it was clear that the secretary was the only person in the organization who had little or no upward mobility. For managers with secretaries, they often created a barrier or buffer between the manager and the world. This actually inhibited the free flow of ideas. SEI offered jobs to all of its secretaries and half of them chose to stay in different roles. 
The company moved to team phones, where a call that bounced from one member of a team went to all the other members. Whoever was free at the moment would pick up. This meant that the client would actually be able to speak to someone knowledgeable rather than leaving a message. It also meant that all members of the team would be aware of the entire business. The elimination of secretaries created the need for more direct access to managers and other employees. Yet the organization was still in offices. This was yet another tension between the emerging culture and structure and the company’s existing workspace.

\section{A Mismatch Between Culture and Workspace}

Since its founding in 1968, SEI had moved about ten times to different locations, seeking to keep up with rapid growth, before it arrived at its headquarters in Oaks in 1996. Over its history, it had started with more conventional offices, with management grouped in one area, and secretaries in cubicles outside of their closed offices. As the organization had reinvented itself, the fit between the company and its workspace had become increasingly uncomfortable.

In 1996, the company had now reached a size where the organization needed its own buildings and campus. The new corporate headquarters presented an opportunity to develop a work environment that would truly reflect the culture of the company and create the foundation for future growth. The campus in Oaks was designed from scratch on 90 acres with an additional 35 adjacent acres and the Perkiomen Creek flowing by the campus.

With a tag line of "New Ways, New Answers," creativity is at the heart of SEI's culture and business. The company is far from the button-down bankers of Wall Street. It is a source of new 
ideas. It is a company that defies commonplace categories. By combining the best competencies of the technology and investment businesses, SEI has created a unique competitive advantage. SEI's people are also uncommon, personifying both entrepreneurial initiative and cooperative teamwork. They are flexible, eager to learn, generous with knowledge and skills, and creative, yet practical. Innovation is everywhere in the company's strategies, products, client relationships and even the physical environment.

The objective of any company is value creation. Part of value creation is growth. How do you create value for relevant shareholders and stakeholders, how do you help employees grow and develop, with responsibility to customers? It is very important that the company’s strategy, whatever strategy you decide to achieve growth, be aligned with the right corporate values and corporate culture. The most difficult thing for any company is realizing values and culture, especially when the environment is changing.

\section{Culture by Design}

The best way to explore the design of SEI offices is to explain why specific design choices were made. Instead of fitting an organization into a preexisting "box" of standard corporate architecture, the goal was to create architecture and organizational designs that truly reflected the culture of the organization. Among the aspects of culture reflected in this internal SEI landscape are:

- Egalitarianism: Ideas are more important than hierarchy. The organization had eliminated hierarchy and secretaries, but the new office literally leveled the playing field. There are no offices. The desks are in large barn-like spaces, with high ceilings and open 
spaces, surrounded by more private conference rooms. The CEO has the same desk and office furniture as everyone else in the company. Personal space is not used to distinguish individuals. Titles and seniority don't matter. While there is hierarchy in the organization, there is no hierarchy in the building and this sets the tone for work there. This is a signal that any individual's ideas are as good as anyone else's. In addition to the office design, the dress code is casual, leveling the playing field, and there are no assigned parking spaces. If the chairman arrives late, he has a long walk.

- Empowerment: Employees are encouraged to act as owners. This is clearly communicated by both the offices on wheels and the ability to change their position in the organization without an edict from on high. While top leaders set the overall vision and strategy, employees are empowered to take themselves to another team in the organization on their own.

- Transparency: In an office without walls, there are no secrets. The overall impact of open architecture is openness in the culture. There are no private conversations. A manager can take the temperature of the team just by listening, knowing when to jump in before a situation gets out of hand. It leads to a lot more openness and interaction, and mentoring and learning. Employees have to become skilled at body language, respecting space and signals such as someone working intently with their eyes down. Eyes up indicates the person is open for conversation. 
- Flexibility: Change is constant. While some organizations might have unmoving marble walls, SEI's offices were designed for flexibility and change. The open design mean that teams can be reconfigured on the fly. When they moved to the new office, each employee whittled down their belongings to just two boxes, and every year there is competition among business units to see who can throw away the most material during "clean up day.” This ensures that employees are ready to move. Creating a space for a new team or initiative is as simple as rolling desks to a new location, hooking up the infrastructure connections and getting to work. People who want life to be completely predictable probably will not do well in this environment.

- Teamwork and interaction: The barn-like open rooms encourage fluid and informal interactions. There is open communication, with everything in the line of sight and nothing higher than a desk to block the interaction. There is no need to gather around the water cooler to exchange information and ideas. It happens everywhere. There is no executive dining room, just a large cafeteria that is in use as a central meeting place throughout the day. There are also small sitting areas throughout the building for spontaneous meetings and informal interactions. A health club in the building helps make the office an engaging and fun place to work. The only closed-door areas are the conference rooms and there are not too many of them.

These are just a few of the messages that are clear and evident in this environment. While many organizations may state their commitment to such principles, embodying these values in the 
structure of the workplace raises the commitment to a whole new level. The organization wears its culture on its sleeve.

\section{Art That Invites Dialogue}

The artwork in SEI's offices also serves a distinctive purpose in building a culture of creativity. While some companies may decorate their offices with nostalgic Remington statues from the Old West, the softly lit cathedrals of the Impressionists or the tranquil landscapes of the Old Masters, SEI's walls feature one of the largest collections of emerging artists in the United States. The more than 2,500 works in the West Collection are designed to be provocative. There are mushrooms growing out of cement walls that look so real that a visitor tried to remove one. There is a set of “marble” heads carved out of a stack of ordinary phone books with an electric turkey carving knife. There are gritty portraits of tattooed biker and prostitutes. A threedimensional cartoonish car is parked in the hallway. This artwork creates an environment of creativity and innovation, where fresh ideas - even shocking ones -are encouraged, and open debate is welcomed.

The central forum for this debate is the Hot Hall. A utility corridor leading between the employee parking lot and gym, this is SEI's own Siberia, where outcast works of art are exiled but certainly not forgotten. If the curators install a new piece in a work area over the weekend, they might have a dozen calls or emails of protest from workers in that area by 10 am Monday morning. One of these objectionable pieces of art, for example, was a series of separate panels depicting a dog being put into a bag and then into a dumpster. It sparked an outcry from 
employees. If two or more employees object to artwork in their area, and their objections are substantive, the works are removed.

But that is not the end of the process. After a week for cooling down and reflection, the artwork is installed in the Hot Hall along with explanations from the curators about the artist's background or intent and some of the early comments from employees. In the case of the dog and the dumpster, the separate panels might be seen as the artist's commentary on how viewers put stories together. As an SEI employee commented, if one looks at the panels in reverse order, they tell the story of a dog being rescued.

There is a computer terminal in the Hot Hall that allows employees and visitors to anonymously make comments on the works there. Many of the comments are posted on the wall so later visitors can see the diverse reactions elicited by the same work of art. In the case of the dog in the dumpster, there have been more than 200 comments. This creates an active and open dialogue across every level and part of the organization that is separate from work discussions but creates a backdrop for such discussions. This sends a clear signal that there are no "sacred cows" that cannot be questioned and challenged.

There is even a process for readoption of the works. Two or more employees from a single area can request to move a work from the Hot Hall to their area. It is up to them to convince their surrounding colleagues that the work should remain (if two or more petition for removal, the work can, of course, go back to the Hot Hall again). As a reward for their courage, the adopters are given the right to curate their own areas, choosing works of art from the entire collection. 


\section{The Business Purpose}

The collection is owned by the West family, so no corporate funds are spent on it. This avoids the necessity of justifying the ROI of the collection, and insulates the company from objections to spending corporate funds on specific pieces of artwork. The collection has been developed and managed independently by curator Paige West and director Lee Stoetzel, so corporate attention remains focused on the business, not collecting art.

Parts of the collection have spent time on loan to some of the leading contemporary art museums in the world (the pieces in most demand are those in the Hot Hall). But a company is not a museum. How is the collection related to the business? It is not a direct relationship. Decisions about the choice of artwork are made based on what the collection needs, not the business. In shaping the collection, they decided early on not to make an explicit connection - for example, focusing on works related to technology - that would limit scope and creativity. Instead, the connection supports the business at a broader level, by encouraging a culture of creativity. By seeking out the most creative, engaging and daring emerging artists, they encourage these qualities in the organization. They tend to buy art in depth, with as many as 100 pieces from a single artist, and seek out artists early in their careers before they are discovered by the broader world. This keeps the collection edgy, experimental and emerging. While SEI's own products are less visible than the art in its hallways, the goal is that the firm's creative combinations of 
technology and investment knowledge, if they could be committed to canvas, would be very much at home as part of this art collection.

The architecture and character of the workplace does have an impact on the type of art that is appropriate. Some artwork would not work in the company's barn-like space or trading-floor atmosphere. In fact, over time, they have found that the realism of photography is the best fit with the SEI work environment. In a speak-your-mind organization, the directness of photography is appreciated. More than half the collection on display in Oaks is now photography, which is also a reflection of a growing interest among contemporary artists in this medium.

\section{From An Embarrassment To An Asset}

When SEI began installing art in the Oaks headquarters, it was a big risk. Some employees were initially embarrassed by the collection. What would conservative bankers think about such an environment? Would it be a liability? Would they be able to convince talented new employees leave behind more traditional Wall Street offices to come to this off-beat environment in Oaks?

Instead, it turned out to be a great asset. Visitors responded favorably and clients even arranged special tours just to see the collection. It was attractive to employees as well. It made it clear immediately that this was a place that took a fresh approach to old problems, and could be a source of new ideas. Investors appreciated the combination of the fiscal conservatism in the design and materials, and the creativity in execution. What was seen by some at first as an embarrassment quickly was recognized as an asset. 
The work environment also was a shock to many managers. They felt naked without any of the accoutrements of power such as an office or a secretary. When the company prepared to move to the new offices, there were "black market” floor plans as employees sought to fit the new environment into their old view of office space. But it didn’t take long after arrival for employees to adjust to the new reality. What looked like chaos without an office plan quickly took on an order of its own. Of course, it wasn't for everyone. Some managers and other employees left the organization, but the ones that remained were those aligned with the organization's culture.

\section{REVOLUTION IS NOT A DEMOCRATIC PROCESS}

While the culture embodied in SEI's new organization and workplace was designed to be egalitarian and empowering to employees, the process of creating this architecture for the organization and the workplace was driven from the top. Because such radical changes are painful for organizations, they cannot be undertaken by committee. In most cases a democratic process will lead to inaction. While revolutions may result in democracies, this does not mean that revolution is a democratic process. Remember that the revolution that led to the US democracy came about as the result of deliberate action by a relatively small group of leaders. The organization will throw many obstacles in the path of change. Many of those at SEI who could not change with the organization left the company, but those who remained became actively engaged in the transition and were aligned with the organization's values. The workplace design helped in this process of alignment by making the culture concrete. 
Although driven from the top, the company's executive committee played a central role in implementing the changes. The CEO took the new model and the underlying principles to this committee - along with the cultural principles it was based upon - and this team of more than a dozen senior managers played a critical role in adopting the changes and carrying them out to the organization. Employees had a choice of whether to go with the new organization or leave, and some chose to leave. Some pushed to see a floor plan, which didn’t exist. Some couldn’t live without corner offices. Since the office redesign was developed in concert with other organizational changes such as the elimination of secretaries, these other changes had also made it clear to employees whether they fit with this culture.

The organization also paid careful attention to the transition process. The transfer to the new workplace was done in stages with CEO Al West moving in the first phase. This allowed the rest of the organization to see what was happening before they moved. It also made it clear that this new workplace would apply to everyone. This transition process also helped create interest in and excitement about the new workplace.

\section{PRINCIPLES OF DESIGN}

What has SEI learned from this decade-long experiment with an innovative workplace design? Among the lessons:

- Embrace the culture: Workplace design should reflect the culture and it should clarify the culture. The design that works so well for SEI would not work for every organization. Even those who admire it may not want to emulate it in their own organizations. The SEI environment is a good one for knowledge workers in an industry that is rapidly changing. 
To the extent that a given company fits this profile, there may be some elements of the SEI experience that could be applicable to their organizations.

The important thing, however, is to think carefully about how an organization's culture and values, whatever they are, can be embodied in the workplace design. Wal-Mart does very well in a corporate headquarters in an old shed with a tin roof. General Electric does very well with a more traditional hierarchical approach and office layout. Companies cannot just change the office without changing the culture and expect to have good results. Instead the two needed to be aligned. Some of SEI's international offices have moved to a similar model, but in others, particularly in joint ventures, there is a need to recognize the limitations of the existing culture and realize that such an informal approach may not work.

Since every culture is different, the solutions will vary widely. But we do need to look beyond the limitations of cookie-cutter designs for workspaces, where every cubicle looks the same. Before creating the office in Oaks, SEI never realized the power of making the culture clear and evident. It is a tremendous asset for communicating and strengthening the culture of the organization, whatever that culture may be.

- Fiscal responsibility: Organizations need to avoid the "edifice complex" seen in many companies that waste a lot of money creating expensive showcases. In designing its buildings, SEI has always sought to be both innovative and fiscally responsible. The whole project was value engineered, using industrial materials rather than commercial. All the floors are made of recycled tires. This facilitates rolling offices and dampens 
sound in open spaces, but also reduces costs as well as being ecologically sound. The building are made of concrete because an earlier plan to employ fieldstone in the Pennsylvania "barn” architecture was revised to reduce costs.

- Build for flexibility: It is not just the internal spaces that are flexible. With a modular structure, SEI can add space in small increments as needed by the business. The buildings were also designed so that they can easily be demolished at the end of their lifespan. Who knows what type of building the company will need in a decade or two? Unlike some of the palaces built by some financial institutions, this was not designed to be a monument. Instead, it was made to be disposable. There are inevitable organizational changes, as well. The new structure has made it much easier for SEI to change.

These are just a few of the early lessons from SEI's experiments with workplace design. The overriding lesson is to take workplace design seriously. It can have a major impact on the organization and there are more opportunities and options than might be apparent at first.

\section{THE IMPACT OF THE WORK ENVIRONMENT}

While SEI has not formally measured the impact of its workspace, the environment has affected the business in many ways. The company's financial performance took off after its move to the new offices, with earnings growth of 40 percent per year from 1996 to 2001, with no increase in workforce. Its average annual return since the move was 28 percent. Even during the dramatic downturn in the investment industry since 2001, SEI was able re-strategize every one of its businesses to continue to post strong performance. It is unlikely that it could have made such 
rapid and dramatic transformations so quickly without the organizational culture and structure to support such moves.

With greater interaction of employees, decisions can be made more quickly, which increases efficiency and effectiveness. These offices, and the culture they reflect, have helped the company grow to become a leader in its market and, as mentioned, to be consistently recognized by Fortune as one of the best places to work in America. This result, based on employee surveys, is a sign that the employees who are with the company find this environment engaging and stimulating. Of course, as noted, the environment is a screening mechanism for new employees so those who join the company clearly appreciate the culture reflected in its office design.

Because the culture is so deeply embedded in the environment, it also has a signaling effect. It signals to new and existing employees about the company's commitment to creativity, teamwork, empowerment and other values. It is a signal to investors that the company is creative and transparent, but also demonstrates a practical sense of frugality in the efficiency of the design and execution. To customers, the workplace signals open communication, fiscal responsibility (reasonable fees) and the ability to develop creative solutions to their challenges. The walls literally can talk, and they speak volumes about the organization.

Beyond this anecdotal evidence, there are broader surveys and studies that indicate the relationship between workplace design and performance. A 2005 report by the British Council for Offices (BCO) and the Commission for Architecture \& the Built Environment (CABE) found that office design affects worker performance by up to 5 percent for individuals and up to 11 
percent for teams. ${ }^{5}$ They pointed to evidence that office design influences a range of factors critical to business performance, including staff retention, knowledge and skills of staff, innovation and creativity, responsiveness to business and technological change. For example, Sun Microsystems, highlighted the report, achieved a 10 percent gain in individual productivity following the introduction of settings designed to enhance the informal interchange of ideas.

On the other hand, we need to recognize that there are potential downsides to innovations in culture and office space. A culture of fun can lead to cynicism as employees see the boundaries between work and personal life blurred. ${ }^{6}$ The move toward open offices, increases interaction but also leads to concerns about higher levels of noise. In a study completed for the American Society of Interior Designers (ASID) by Yankelovich Partners, 70 percent of office workers polled agreed that productivity would increase if office noise would decrease. But a subsequent study (conducted for ASID by L.C. Williams and Associates) found that 81 percent of those polled reported they were not concerned with office noise. ${ }^{7}$ In SEI's experience, there is an adaptation that occurs over time, as employees adjust to the new environment. People tend to speak in a lower voice and they also get used to the level of noise in the open rooms, which ultimately provides some privacy by creating a natural "white noise.” Once they have been in the environment for a little while, people have no hesitation to discuss any issue in this environment. And the noise levels, which could initially be seen as a distraction, can be energizing, like the bustle of a trading floor.

Even with a flexible work environment, change takes its toll on an organization. It is impossible to truly change the wheels of a race car on the fly. It always requires a pit stop. There is always 
some loss of momentum before the new strategy gains traction and takes off. But an organization designed for speed and flexibility - like an experienced pit crew - can speed up the change to reduce the impact of these shifts in direction.

SEI's workplace design and artwork deliver a wide range of benefits that ultimately help to drive corporate performance, as illustrated in Figure 1. The values and culture provide the blueprint for SEI's workplace and artwork. This leads to many benefits for the organization, including attracting and retaining employees, encouraging teamwork and interaction, facilitating communication and transparency, encouraging creativity and signaling to all stakeholders about innovation and fiscal responsibility. These benefits, in turn, contribute to continuous innovation, growth and achievement of corporate objectives.

\section{CONCLUSIONS}

Creating and changing corporate culture is one of the toughest yet critical management tasks. While many leaders recognize the importance of symbolism in their own actions and communications, much more rarely do they recognize that one of the best ways to make culture concrete is to embed it into the design of the workplace and artwork. This makes what are often abstract concepts very direct and unequivocal.

SEI took an innovative approach to its workplace design, starting with a clean slate to create an environment that would truly reflect and support its distinctive culture. The experience after nearly a decade is that the design has proven its flexibility in adapting to changing environments and business strategies. While it may not be the right solution for every organization, nor is it the 
only solution for SEI's own culture, it does indicate that there are many more varied approaches to workplace design than the typical off-the-shelf solutions employed by most companies.

By giving careful thought to the company's culture and designing an environment to support it, organizations can strengthen their culture and values and link them more directly to the work of the organization. They also can design their workspaces for more effective responses to the inevitable changes in the business environment. In this context, SEI's solution represent one of many. It is not so much a recipe to emulate as an illustration of the role of workplace design and art in bringing alive the culture and values of the organization. This, in turn, creates a unique organizational design that makes it easier to implement creative strategic directions for the benefit of all stakeholders. 


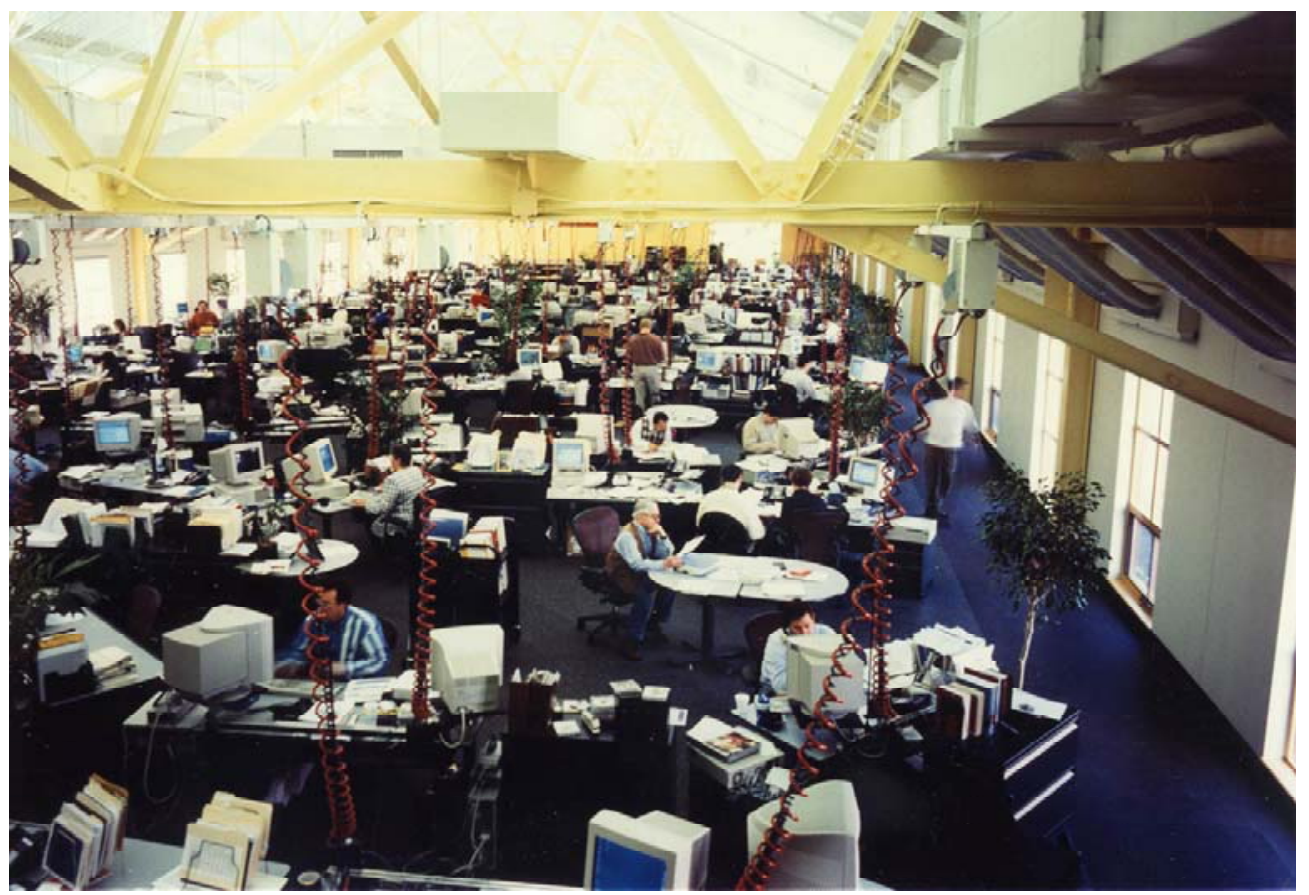

With desks and chairs on wheels, employees can reconfigure their teams and workspace in the barn-like offices of SEl. Red "pythons" instantly connect employees to electricity, phones and the computer network.

(C) 2005 SEI Investments Inc.

[SEE POWERPOINT FILE FOR ADDITIONAL PHOTOS] 


\section{NOTES}

${ }^{1}$ For a review the literature on the "culture of fun," see Peter Fleming, "Workers Playtime? Boundaries and Cynicism in a "Culture of Fun” Program,” The Journal Of Applied Behavioral Science, Vol. 41 No. 3, (September 2005), pp. 285-303.

${ }^{2}$ See, for example, Hofstede, G., Neuijen, B., Ohayv, D.D., Sanders, G. (1990), "Measuring Organizational Cultures: A Qualitative and Quantitative Study across Twenty Cases", Administrative Science Quarterly, Vol. 35 No.June 1, pp.286-316.

3 “News Briefs,” HR Focus. New York: Vol 82, Issue 12 (Dec 2005), pg. 9

4 Jerry Wind and Colin Crook, The Power of Impossible Thinking, Philadelphia: Wharton School Publishing, 2004.

${ }^{5}$ Karen Higginbottom, “A Place for Productivity,” Estates Gazette, issue 521 (May 28, 2005), p. 64-65.

${ }^{6}$ Fleming, 2005.

${ }^{7}$ Tiernan Carsia, “Designing Workspaces for Higher Productivity,” Occupational Health \& Safety Waco Vol. 71, Issue 9 (September 2002). pp. 192-194. 